\title{
Studi Kesiapan Daerah Untuk Investasi Infrastruktur Sosial Berbasis Pembiayaan Non APBN/APBD
}

\section{Regional Readiness Study for Sosial Infrastructure Investment Based on Non-APBN/APBD}

\author{
Yervi Hesna $^{1, a)}$, Akhmad Suraji ${ }^{1, b)}$, Suchi Rahmadani ${ }^{2, c)}$ \& Eka Ikhwanul Satria ${ }^{2, d)}$ \\ ${ }^{1)}$ Dosen Jurusan Teknik Sipil, Fakultas Teknik, Universitas Andalas \\ ${ }^{2)}$ Alumni Jurusan Teknik Sipil, Fakultas Teknik, Universitas Andalas
}

Koresponden : ${ }^{a}$ yervi@eng.unand.ac.id, ${ }^{b)}$ akhmad.suraji@gmail.com,

c)suchirahmadi640@gmail.com \& d)eka.ikhwanul.satria@gmail.com

\begin{abstract}
ABSTRAK
Pembangunan Infrastruktur harus dipenuhi dari sumber pendanaan lain guna melakukan akselerasi pembangunan infrastruktur di Indonesia yang pemenuhannya dapat dilakukan dengan menggunakan skema pendanaan alternative seperti Kerjasama Pemerintah dan Badan Usaha (KPBU) dan Pembiayaan Infrastruktur Non-Anggaran (PINA). Skema pendanaan alternatif ini dapat dilakukan untuk pemenuhan kebutuhan pembangunan infrastruktur indonesia. Setiap daerah yang ada di indoneseia dapat menjalanlan skema KPBU dan PINA untuk memenuhi kebutuhan infrastruktur, khususnya infrastruktur sosial. Maka dari itu perlu dilakukan penelitian untuk menganalisis kesiapan daerah dalam investasi infrastruktur sosial berbasis PINA di Sumatera Barat. Penelitian ini dilakukan dengan menganalisis kesiapan daerah mengunakan faktor-faktor penentu kesiapan daerah berupa : (1) kesiapan regulasi daerah yang mendorong investasi infrastruktur, (2) kesiapan dari kemajuan ekonomi daerah, (3) kesiapan dari perangkat operasional. Dari hasil penelitian menunjukkan bahwa Sumatera Barat belum mengamanatkan kebijakan PINA dalam RPJMD dan untuk masih melakukan penyusunan regulasi terkait PINA.
\end{abstract}

Kata Kunci : manajemen aset infrastruktur, infrastruktur sosial, investasi, kesiapan daerah, PINA

\section{PENDAHULUAN}

Manajemen Aset Infrastruktur adalah suatu ilmu pengetahuan, program dan tindakan untuk mengelola infrastruktur agar bisa berfungsi berkelanjutan, secara ekonomis, efisien, efektif dan sesuai dengan prinsip sustainability (Suprayitno \& Soemitro 2018).

Penyediaan infrastruktur adalah kegiatan yang meliputi pekerjaan konstruksi untuk membangun atau meningkatkan kemampuan infrastruktur dan atau kegiatan pengelolaan infrastruktur dalam rangka meningkatkan kemanfaatan infrastruktur. Pola lama dalam penyediaan infrastruktur bahwa hampir seluruh pembangunan infrastruktur dilaksanakan oleh pemerintah. Pendekatannya biasanya sentralistis, terpusat pada pemerintahan pusat. Penyediaan infrastruktur dapat juga didanai oeh BUMN dan BUMD, sehingga karena berasal dari pendanaan negara, maka pemerintah berfungsi ganda sebagai regulator dan operator.

Paradigma baru dalam penyediaan infrastuktur adalah bahwa pemerintah hanya berkonsentrasi pada infrastruktur-infrastuktur dasar dan non-commercially viable tetapi economically feasible, sedangkan infrastruktur yang sepenuhnya commercially viable diserahkan pembangunannya kepada pihak swasta (Martini 2011). Karena ada keterlibatan 
unsur swasta dalam penyediaan infrastruktur, dengan paradigma baru ini memungkinkan dipisahkannya fungsi regulator dan operator pada pemerintah. Disamping sektor swasta, koperasi juga diperkenankan untuk ikut serta dalam pendanaan penyediaan infrastruktur. Pendekatan yang biasanya sentralistis, dengan paradigma baru memungkinkan pemerintah daerah juga ikut berperan serta.

Peraturan Presiden No 38 Tahun 2015 tentang Kerjasama Pemerintah Dengan Badan Usaha Dalam Penyediaan Infrastruktur merupakan dasar pelaksanaan/regulasi terbaru yang mengatur mekanisme pelaksanaan skema KPBU dalam penyediaan infrastruktur di Indonesia. Perpres No 38 Tahun 2015 ini telah membagi 19 kategori infrastruktur yang dikelompokkan menjadi infrastruktur ekonomi dan infrastruktur sosial. Infrastruktur sosial dimaksudkan infrstruktur yang berfungsi untuk memberikan layanan sosial bagi masyarakat. Karakteristiknya merupakan infrastruktur yang non commercially viable namun economically feasible.

Yang menjadi perhatian dalam skema penyediaan infrastruktur sosial adalah belum banyaknya investor yang tertarik berinvestasi pada infrastruktur sosial (Northern Ireland Assembly 2016). Hal tersebut dikarenakan daya tarik dari infrastruktur sosial yang masih rendah. Karena infrastruktur sosial lebih identic dengan infrastruktur yang tidak bersifat komersil, sehingga dianggap memiliki skala ekonomi kecil (Prasetyo \& Firdaus 2009).

Di lain pihak kapasitas pemerintah daerah sebagai Penanggung Jawab Proyek Kerjasama (PJPK) juga masih terbatas untuk memasarkannya. Belum ada organisasi atau perangkat satuan kerja di daerah yang bertanggungjawab untuk melaksanakan Kerjasama Pemerintah Badan Usaha (KPBU) sehingga instrument kebijakan pelaksanaan KPBU juga belum established. Sementara itu dukungan pemerintah secara nasional dalam pelaksanan KPBU juga belum masif. Skema pembiayaan investasi non-anggaran pemerintah atau PINA akan melengkapi skema-skema pembiayaan yang sudah ada (Andi 2017).

Berlandaskan keadaan-keadaan diatas perlu kiranya untuk mengetahui kesiapan pemerintah daerah baik provinsi maupun kota/kabupaten untuk melaksanakan skema-skema pendanaan melalui Kerjasama Pemerintah Badan Usaha, dalam upaya mempercepat pembangunan dan penyediaan infrastruktur khususnya infrastruktur sosial. Tujuan penelitian ini adalah untuk mengidentifikasi tingkat kesiapan daerah di Sumatera Barat dalam pelaksanaan investasi infrastruktur sosial yang diterjemahkan melalui seberapa besar kesiapan daerah untuk melakukan investasi infrastruktur sosial berbasis investasi non APBN/APBD (PINA).

\section{KESIAPAN DAERAH DALAM INVESTASI}

Pelimpahan urusan investasi menjadi urusan yang otonom bagi daerah telah menimbulkan persaingan yang kuat antar daerah untuk menarik investasi ke daerahnya. Hal ini memberikan tanggung jawab yang besar bagi masing - masing daerah agar mampu menciptakan sitem keterkelolaan investasi daerah untuk memberikan pelayanan prima kepada calon investor. Oleh karena itu, agar dapat menciptakan sebuah sistem keterkelolaan investasi yang baik, daerah tersebut haruslah memiliki kesiapan yang baik dari segi kapasitas pemerintah maupun otonomi kelembagaannya untuk menjalankan urusan investasi.

Pemerintah daerah dituntut agar mampu memberikan iklim kondusif untuk berinvestasi dan berusaha. Pemerintah daerah harus mampu menyelenggarakan sistem tata kelola pemerintahan yang mendukung bagi kegiatan investasi infrastruktur (Rahardjo \& Bermawi 2015). Keberhasilan daerah untuk meningkatkan daya tarik terhadap investasi salah satunya bergantung kepada kemampuan daerah dalam merumuskan berbagai kebijakan yang berkaitan dengan investasi dan dunia usaha, serta peningkatan kualitas pelayanan terhadap masyarakat (Soleh 2005). 
Dengan demikian, kesiapan daerah dalam investasi dapat dilihat dari 3 unsur diantaranya :

a. Pemerintahan daerah, kesiapan pemerintah daerah dalam investasi dapat dilihat dari regulasi pemerintah daerah tersebut dan bagaimana pemerintah membuat kebijakan maupun peraturan mengenai investasi.

b. Daerah, kesiapan dapat dilihat dari infrastruktur fisik potensial yang ada didaerah tesebut.

c. Masyarakat, kesiapan dilihat dari peningkatan kualitas pelayanan masyarakat serta pertumbuhan ekonominya.

Dalam menganalisis kesiapan pemerintah daerah dalam investasi infratsruktur sosial maka diperlukan faktor-faktor yang menentukan kesiapan suatu daerah sebagai berikut (Kementrian Pekerjaan Umum dan Perumahan Rakyat 2017) :

Tabel 1. Faktor-Faktor Kesiapan Daerah dalam Penyelenggaraan PINA

\begin{tabular}{|c|c|c|}
\hline $\begin{array}{l}\text { KESIAPANDAERAHDALAM } \\
\text { REGULASIYANG } \\
\text { MENDORONGINVESTASI } \\
\text { INFRASTRUKTUR }\end{array}$ & $\begin{array}{l}\text { KESIAPAN DAERAH DALAM } \\
\text { KEMAJUANPEREKONOMIAN }\end{array}$ & $\begin{array}{l}\text { KESIAPANDAERAH DALAM } \\
\text { PERANGKAT OPERASIONAL } \\
\text { LAINNYA }\end{array}$ \\
\hline $\begin{array}{l}\text { - RPJMD; } \\
\text { - Regulasi Daerah Tentang PINA dif } \\
\text { Bidang Infrastruktur Sosial } \\
\text { - Kemudahan Perizinan; } \\
\text { - Kemudahan Pembabasan Lahar; } \\
\text { - Kemudahan Interkasi Pemda - } \\
\text { Pelaku Usaha }\end{array}$ & $\begin{array}{l}\text { - PDRB; } \\
\text { - PAD; } \\
\text { - Realisasi Investasi; } \\
\text { - Tingkat Daya Beli Masyarakat } \\
\text { (PPP/Pundasing Pourer Parity); } \\
\text { - Indeks Kebijakan Fiskal / IKF; }\end{array}$ & $\begin{array}{l}\text { - Perangkat Institusional; } \\
\text { - Perangkat Organisasi daerah; } \\
\text { - SDM Yang Memahami PINA; } \\
\text { - Pengalaman Dalam Penyelenggaraan } \\
\text { PINA. }\end{array}$ \\
\hline
\end{tabular}

Sumber : Kementerian PUPR ,Investasi Pendanaan Infrastruktur PUPR Kewenangan Daerah

\section{KEBIJAKAN INVESTASI INFRASTRUKTUR DAERAH}

Untuk mempercepat pembangunan infrastruktur, pemerintah terus berusaha untuk melakukan langkah perbaikan melalui penyempurnaan regulasi tentang kerjasama pemerintah dengan badan usaha dalam penyediaan infrastruktur. Perbaikan regulasi ini penting agar dapat menciptakan iklim investasi dan mendorong keikutsertaan badan usaha dalam penyediaan infrastruktur (Tambunan 2006).

Kebijakan yang mengatur kerjasama pemerintah dengan badan usaha dalam penyediaan infrastruktur telah mengalami empat kali perubahan. Pengaturan pertama dikeluarkan di masa pemerintahan Presiden Susilo Bambang Yudoyono dengan dikeluarkannya Perpres No. 67 tahun 2005 tentang Kerjasama Pemerintah dengan Badan Usaha (KPBU) dalam Penyediaan Infrastruktur. Perpres tersebut kemudian mengalami tiga kali penyempurnaan, yaitu Perpres No. 13 tahun 2010, Perpres No. 56 tahun 2011, dan terakhir Perpres No. 38 tahun 2015. Salah satu perubahan penting dalam peraturan yang baru ini adalah perluasan jenis proyek yang dapat dikerjasamakan, yaitu di bidang infrastruktur social dan diadakannya skema pembayaran atas ketersediaan layanan (availability payment).

Skema KPBU sebenarnya telah dimulai pada tahun 1991 pada saat Bank Dunia menawarkan pinjaman TAP4I (Technnical Assistance Project for Public \& Private Provision of Infrastructure) kepada Pemerintah Indonesia. Kemudian ADB juga memberi pinjaman lain seperti PPITA (Private Provision of Infrastructure Technical Assistance). Namun realisasi proyek infrastruktur dengan skema KPBU hingga saat ini masih menghadapi beberapa kendala, seperti kurangnya kapasitas PJPK untuk mempersiapkan proyek kerjasama, banyaknya perizinan yang harus dipenuhi, dan lambatnya proses pengadaan tanah, merupakan 
contoh faktor-faktor yang menyebabkan lambatnya realisasi proyek dengan skema KPBU (Utomo 2016, Martini 2011).

Untuk mengatasi permasalahan keterlambatan dalam pengadaan tanah, Pemerintah kemudian mengeluarkan regulasi baru melalui Perpres Nomor 30 tahun 2015 tentang Penyelenggaraan Pengadaan Tanah bagi Pembangunan untuk Kepentingan Umum. Sedangkan untuk mengatasi masalah pengurusan perizinan, telah dilakukan perbaikan dan koordinasi antar instansi, agar proses perizinan dapat dilakukan dengan cepat dan lancar. Bimbingan teknis dan lokakarya pun dilakukan untuk meningkatkan kapasitas PJPK dalam penyiapan proyek kerjasama.

\section{METODE PENELITIAN}

\section{Pengumpulan Data Sekunder}

Data sekunder, untuk penelitian ini, dikumpulkan melalui internet dan database yang berupa :

a. Rencana Pembangunan Jangka Menengah Daerah (RPJMD), 19 kabupaten/kota, Sumatera Barat

b. Pendapatan Asli Daerah (PAD), 19 kabupaten/kota, Sumatera Barat

c. Produk Domestik Regional Bruto (PDRB), 19 kabupaten/kota, Sumatera Barat

d. Kapasitas Fiskal Daerah, 19 kabupaten/kota, Sumatera Barat

e. PMDN/PMA Sumatera Barat

f. Puchasing Power Parity (PPP)

g. Laporan Tata Kelola Ekonomi Daerah (TKED)

\section{Survei Instansional Dengan Kuisioner}

Kuisoner diajukan pada Bagian Ekonomi dan Sarana Prasarana Bappeda yang terdapat pada lima daerah di Sumatera Barat yaitu Kota Padang, Kota Payakumbuh, Kota Bukittingi, Kota Pariaman, dan Kabupaten Tanah Datar yang dipilih berdasarkan pendapatan asli daerah, produk domestik regional bruto dan kapasitas fiskal terbesar dibandingkan dengan 1 daerah yang memiliki Pendapatan Asli Daerah terkecil.

Berdasarkan pada faktor dan variabel penentu kesiapan daerah dalam pendayagunaan PINA di atas maka pada kuisioner ini terdapat 5 instrumen utama yang menjadi pokok pembahasan yang dikembangkan lagi menjadi 63 pertanyaan untuk melihat tingkat kesiapan daerah terhadap investasi infrastruktur daerah. Tabel berikut merupakan rekapitulasi pertanyaannya.

Tabel 2. Perangkat Regulasi Daerah/Perda/Pergub/Perbup/Perwalkot

\begin{tabular}{|c|c|}
\hline No & PERANGKAT REGULASI DAERAH / PERDA/ PERGUB/ PERBUB/ PERWALKOT \\
\hline 1 & Regulasi Daerah Tenkang Imestasi dad/ ałau Pembiayaan Infrastudkur Fasilitas Perkotaan \\
\hline $\mathbf{Z}$ & Regulasi Daerah Tentang Immestasi dand atau Pembianaan Infrastruktur Fasilitas Pendidikan \\
\hline $\mathbf{3}$ & $\begin{array}{l}\text { Requlasi Daerah Tentang Imestasi dand atau Pembianaan Infrastrukth Fasilitas Sarana dan Prasarana } \\
\text { Olahraga serta Kesenian }\end{array}$ \\
\hline 4 & Regulasi Daerah Tentang Immetasi dad/ atau Pembiayaan Infrastruktur Kanwasan \\
\hline 5 & Regulasi Dacrah Tentang Immestasi dan/ atau Pembiayaan Infrastruktur lembaga Pemasyarakatan \\
\hline 6 & Regulasi Dacrah Tentang Immestasi dan/ atau Pembiapaan Infrastruthu Perumahan Rakyat \\
\hline 7 & Regulasi Daerah Tentang Imrestasi dan/ ałau Pembianaan Infrastruktur Kesehatan \\
\hline $\mathbf{8}$ & 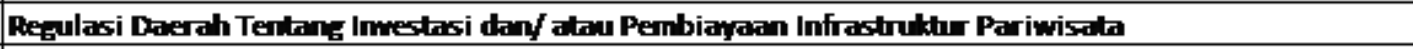 \\
\hline 9 & Regulasi Daerah Tentang Kerjasama Pemda dan Badan Lbaha unduk Propek Infrastruktur Sosial \\
\hline 10 & Regulasi Daerah Tentang Optimalisasi dan Pengusahaan Aset Infrastruktur Daerah \\
\hline
\end{tabular}


Tabel 3. Organisasi Perangkat Daerah untuk Pelenggaraan Investasi Infrastruktur Sosial di Daerah

\begin{tabular}{|c|c|}
\hline No & ORGANISASI PERANGKAT DAERAH UNTUK PELENGGARAAN INVESTASI INFRASTRUKTUR SOSIAL DI DAERAH \\
\hline 1 & 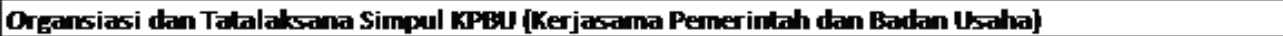 \\
\hline $\mathbf{Z}$ & 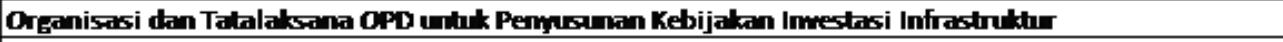 \\
\hline 3 & Organisssi dan Tatalaksana OPD uhtuk Perencanaan Imeskasi Infrastruthr \\
\hline 4 & Organisasi dan Tatalaksana OPD untuk Prioritasi Immestasi Infrastruktur \\
\hline 5 & Organisasi dan Tatalaksana OPD unduk Pempiapan Perangkat Immestasi Infrastruktur \\
\hline 6 & Organisasi dan Tatalaksana OPD untuk Skema Pendanaan Immestasi Infrastruktur \\
\hline 7 & Organisessi dan Tatalaksana OPD unhk Promosi Imestasi Infrastiuktur \\
\hline 8 & 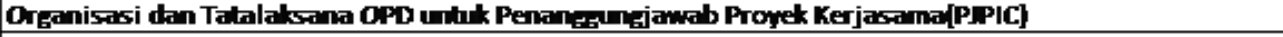 \\
\hline 9 & 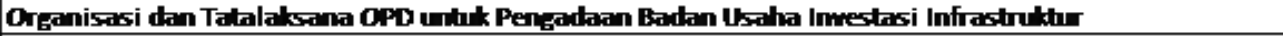 \\
\hline 10 & Organiswi dan Tatalaksana OPD unthk Pengawasan Pelaksanaan Imeskasi Infrastruktur \\
\hline 11 & 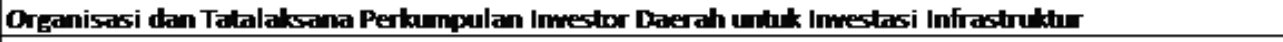 \\
\hline 12 & Organisessi dan Tałalaksana Perkumpulan Konsultan Daerah unduk Immestasi Infrastruktur \\
\hline 13 & Organisasi dan Tatalaksana Pusat Kajian/ Pusat Shodi di Daerah untuk Immestasi Infrastruthu \\
\hline 14 & 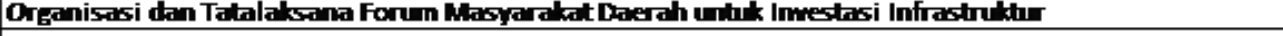 \\
\hline 15 & Organisasi dan Tatalaksana lembaga Diklat di Daerah unht Immestasi Infrastruktur \\
\hline
\end{tabular}

Tabel 4. Perangkat Institutional Daerah untuk Penyelenggaraan Investasi Infrastruktur Sosial di Daerah Berupa Standard Operating Procedure

\begin{tabular}{|c|c|}
\hline No & $\begin{array}{l}\text { PERANGKAT INSTITUTIONAL DAERAH UNTUK PENYELENGGARAAN INVESTASI INFRASTRUKTUR SOSIAL DI } \\
\text { DAERAH BERUPA STANDARD OPERATING PROCEDURE }\end{array}$ \\
\hline 1 & SOP Penpeleneforaan Immestasi dan/ atau Pembiazaan Infrastruktur oleh Penda \\
\hline $\mathbf{z}$ & SOP Perencanaan, Penyiapan dan Transelsi Inmestasi Infrastruktur oleh Pemola \\
\hline $\mathbf{3}$ & SOP Penerapan Skema Pembiayaan untuk Imesłasi Infrastruktur oleh Pemda \\
\hline 4 & SOP Pengadaan Badan Ubaha Immestasi Infrastruktur oleh Pemda \\
\hline 5 & SOP Penpusanan Standar Perjanjian Kerjasama Imestasi Infrastruktur oleh Penda \\
\hline 6 & SOP Monitoring dan Evaluasi Proyek Imestasi Infrastruktur oleh Pemerintah Daerah \\
\hline 7 & SOP Perizinan Imestasi Infrastruktur oleh Pemda \\
\hline $\mathbf{8}$ & SOP Dukangan Politik DPRD untuk Immetasi Infrastinkthr Daerah \\
\hline $\mathbf{9}$ & SOP Manajemen Portofolio atau Manajemen Stratrgi Imestasi Infrastruktur oleh Pemda \\
\hline 10 & SOP Manajemen Pernrograman Immestasi Infrastruktur oleh Pemda \\
\hline 11 & SOP Manajemen Proyek Impestasi Infrastruktur oleh Pemda \\
\hline 12 & SOP Manajemen Aset Infrastinuktur oleh Pemda \\
\hline 13 & SOP Analisis Resiko dan Penjaminan Imesłasi Infrastruktur oleh Pemda \\
\hline 14 & SOP Analisis Biaya Sepanjang Siklus Hidhp Infrastruktur oleh Penda \\
\hline 15 & SOP Penpelesaian Sengketa Imestasi Infrastruktur oleh Pemda \\
\hline
\end{tabular}

Tabel 5. Perangkat Sdm Daerah Untuk Pelaksanaan Investasi Infrastruktur Sosial Oleh Pemda

\begin{tabular}{|c|c|}
\hline No & PERANGKAT SDM DAERAH UNTUK PELAKSANAAN INVESTASI INFRASTRUKTUR SOSIAL OLEH PEMDA \\
\hline 1 & SDM di OPD Pemda Lulusan SZ Imestasi dan / atau Pembiayaan Infrastruktur \\
\hline $\mathbf{z}$ & SDM di OPD Penda Iulusan Pelatihan Imrestasi dan / atau Penbiaz̧aan Infrastruktur \\
\hline 3 & SDM di OPD Penda Tersertifikasi Ahli PPP / KPBUU Penyediaan Infrastruktur \\
\hline 4 & SDM di OPD Pemda Berpengalaman Dalain Perencanaan Proyek KPtgu Infrastruthr \\
\hline 5 & SDM di OPD Pemda Berpengalaman Dalam Penyiapan Proyek KPBOU Infrastruthr \\
\hline 6 & SDM di OPD Pemda Beppengalaman Dalam Trangaksi Proyek KPBSU Infrastruktur \\
\hline 7 & SDM di OPD Pemda Berpengalaman Dalam Perjanjian KPBU Infrastruthu \\
\hline 8 & 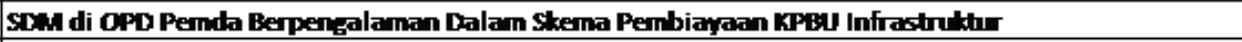 \\
\hline $\mathbf{9}$ & SDM di OPD Pemda Memahami Tata Pempelengraraan KPBU Infrastruktur Sosial \\
\hline 10 & SDM di OPD Penda Memaharni Valure for Mancy Fest Imestasi Infrastruktur \\
\hline 11 & SDM di OPD Pemda Memahami Resikes dan Penjaminan Imestasi Infrastruktur \\
\hline 12 & SDW di OPD Penda Memahami Penyzkesaian Sengkefu Immestasi Infrastruktur \\
\hline 13 & SDW di OPD Penda Memahami Market Sounding Imretasi Infrastruktur \\
\hline 14 & SDCM di Konsultan Penda Ahli di Bidang Imestasi dan / atau Pembiayaan Infrastruktur \\
\hline 15 : & SDM di Konsultan Pemda Ahli di Bidang PPP / KPBSU Infrastruktur \\
\hline
\end{tabular}


Tabel 6. Perangkat Pengetahuan dan Pengalaman Daerah Dalam Investasi Infrastruktur Sosial

\begin{tabular}{|c|c|}
\hline No & PERANGKAT PENGETAHUAN DAN PENGALAMAN DAERAH DALAM INVESTASI INFRASTRUKTUR SOSIAL \\
\hline 1 & Pengalaman Penda Melaksanakan KPBYI unht Penyediaan Infrastruktur Sosial \\
\hline $\mathbf{2}$ & Pengalaman Penda Mempusm Proyek Strateqis Daerah yang Dibiayai Non-APBAyD \\
\hline 3 & Pengalaman Pemda Melaksanakan FeD/Workshop/ Seminar KPPGJ Infrastruktur \\
\hline 4 & Pengalaman Pemda Mengikuti Pertemuan Tentang KPBU Infrastruktur Sosial \\
\hline 5 & Pengalaman Pemda Membahasimmestasi Infrastruktur Sosial Mon-APBAy, \\
\hline 6 & Pengalaman Penda Menpusan Rencana Program Immestasi Infrastruktur Sosial \\
\hline 7 & Pengalaman Penda Menerima Prakarsa Badan Usala untuk Imestasi Infrastruktur Sosial \\
\hline 8 & Pengalaman Penda Mengzumakan Skema Pembiayaan NonPemerintah Infrastruktur Sosial \\
\hline
\end{tabular}

Kuisioner yang digunakan menggunakan Skala Likert dengan skala 1 - 5 dengan arti skala dari rentang tidak siap - sangat siap. Untuk indeks kesiapan daerah ditentukan seperti berikut :

Skor akhir 0\%-20\% = Tidak Siap

Skor akhir 20,01\%-40\% = Kurang Siap

Skor akhir 40,01\%-60\% = Cukup Siap

Skor akhir 60,01\%-80\% = Siap

Skor akhir 80,01\%-100\% = Sangat Siap

\section{HASIL DAN PEMBAHASAN}

\section{Kesiapan Pemerintah Daerah dalam Regulasi yang Mendorong Investasi Infrastruktur Sosial}

Dari segi regulasi daerah dapat dilihat bahwa secara Umum daerah daerah yang disurvei berada pada kondisi SIAP, kecuali daerah Payakumbuh yang berada pada kondisi CUKUP SIAP. Kota Payakumbuh yang belum menyusun regulasi untuk PINA dalam bidang Infrastruktur Sosial. Hal ini disebabkan, Kota Payakumbuh masih mengandalkan APBD untuk membiayai infrastruktur. Dari hasil wawancara diketahui bahwa hal ini disebabkan daerah-daerah di Sumatera Barat ini umumnya memang belum pernah meggunakan program PINA untuk pembangunan infastruktur karena biasanya dana yang dibutuhkan untuk pembangunan infrastruktur bisa dicukupi oleh APBN dan APBD sehingga daerah-daerah ini masih berada pada tahap perecanaan dan penyusunan peraturan-peraturan daerah yang akan mengatur segala hal mengenai investasi infrastruktur tersebut. Berikut adalah grafik yang menampilkan tingkat kesiapan daerah-daerah yang disurvei berdasarkan Regulasi Daerahnya.

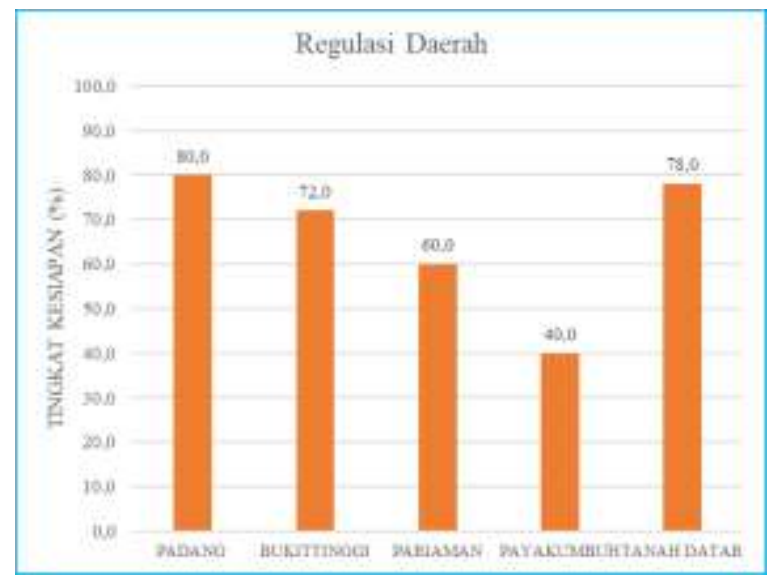

Gambar 1. Tingkat Kesiapan Daerah Berdasarkan Regulasi 


\section{a. Organisasi Perangkat Daerah}

Pada segi Organisasi Perangkat Daerah, hasil yang didapatkan dari survei kuisioner menunjukkan bahwa seluruh daerah yang disurvei berada pada kondisi SIAP, kecuali daerah payakumbuh. Berdasarkan hasil wawancara diketahui hal ini dikarenakan Organisasi yang secara khusus bertanggung jawab untuk mengurus dan mengelola investasi infrastruktur sosial memang belum ada, akan tetapi pada instansi pemerintah lain sudah ada bagian yang diberi tanggung jawab untuk mengelola hal tersebut. Berikut adalah grafik yang menampilkan tingkat kesiapan daerah-daerah yang disurvei berdasarkan Organisasi Perangkat Daerahnya.

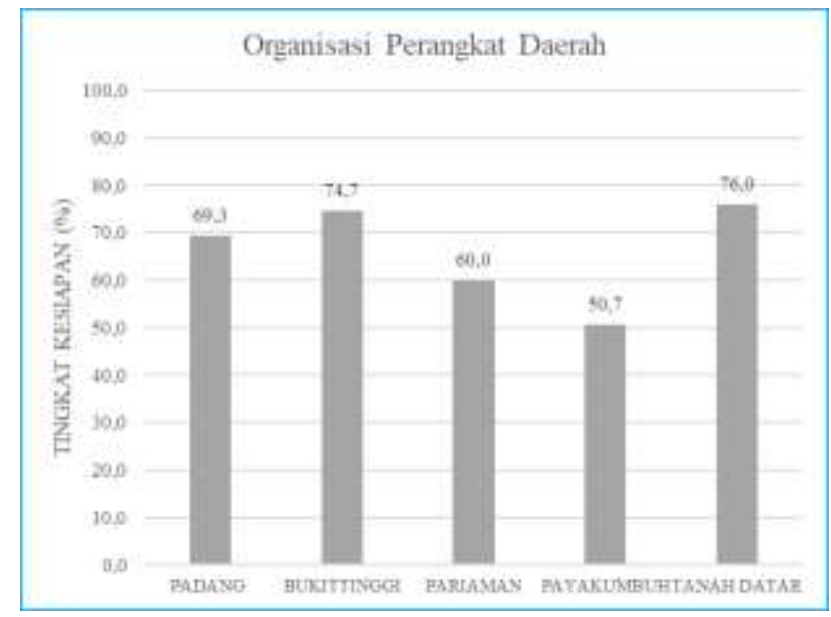

Gambar 2. Tingkat Kesiapan Daerah Berdasarkan Organisasi Perangkat Daerah

\section{b. Perangkat Institusional}

Jika ditinjau dari segi perangkat institusional yang ada maka hasil nya hampir sama dengan instrumen-instrumen sebelumnya dimana kota padang, kota bukittinggi dan kabupaten tanah datar berada pada kondisi SIAP sedangkan kota pariaman dan kota payakumbuh berada pada kondisi CUKUP SIAP. Alasannya pun hampir serupa karena perangkat institusi yang mengatur sistem administrasi, manajemen dan teknis yang berkaitan dengan PINA memang belum ada.

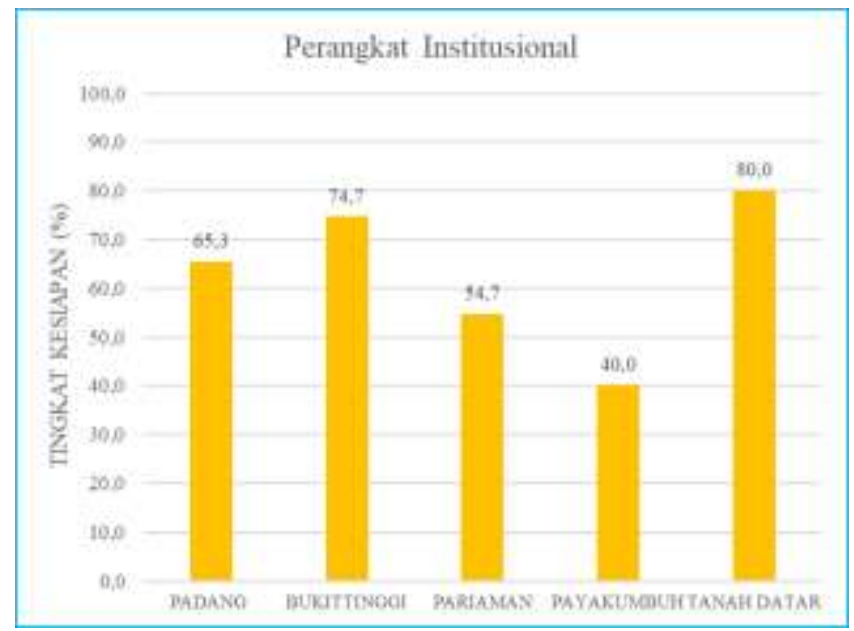

Gambar 3. Tingkat Kesiapan Daerah Berdasarkan Perangkat Institusional 


\section{c. Perangkat SDM daerah}

Pada bidang SDM yang ada diperangkat daerah, skor yang didapatkan daerahdaerah yang disurvei memperoleh skor yang cenderung lebih rendah jika dibandingkan dengan instrumen-instrumen sebelumnya, hal ini dapat dilihat bahwa kota padang kota pariaman dan kota payakumbuh berada pada kondisi CUKUP SIAP, sedangkan untuk Kota Bukittinggi dan kabupaten tanah datar berada pada kondisi SIAP. Hal ini dijelaskan pada saat wawancara bahwa hal ini disebabkan karena belum ada SDM yang bekerja secara profesional dalam perencanaan, penyiapan dan transkasi serta pelaksanaan investasi infrastruktur sosial yang menggunakan skema pembiyaan PINA. Berikut adalah grafik yang menampilkan tingkat kesiapan daerah-daerah yang disurvei berdasarkan SDM pada Perangkat Daerahnya.

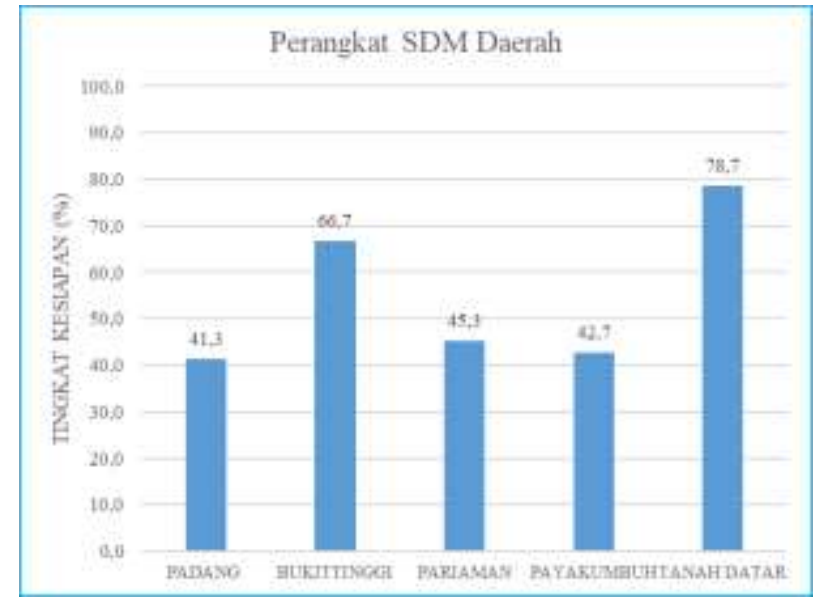

Gambar 4. Tingkat Kesiapan Daerah Berdasarkan SDM Daerah

\section{d. Pengetahuan dan Pengalaman Daerah}

Hampir serupa dengan instrumen SDM yang ada pada perangkat daerah, instrumen Pengetahuan dan Pengalaman yang telah digunakan serta pelaksanaan investasi infrastruktur menggunakan skema pembiayaan PINA juga berada pada kondisi SIAP untuk kota bukittingi dan tanah datar sedangkan untuk kota padang, kota pariaman dan kota payakumbuh berada pada kondisi CUKUP SIAP.

Pada saat wawancara dijelaskan bahwa pengetahuan dan pengalaman daerah mengenai PINA berada pada kondisi yang cukup rendah adalah karena peraturan presiden mengenai PINA bisa dikatakan masih baru, dan baru disosialisasikan oleh pemerintah provinsi, akan tetapi sebelumnya sudah ada skema yang mirip yaitu KPBU dan PPP.

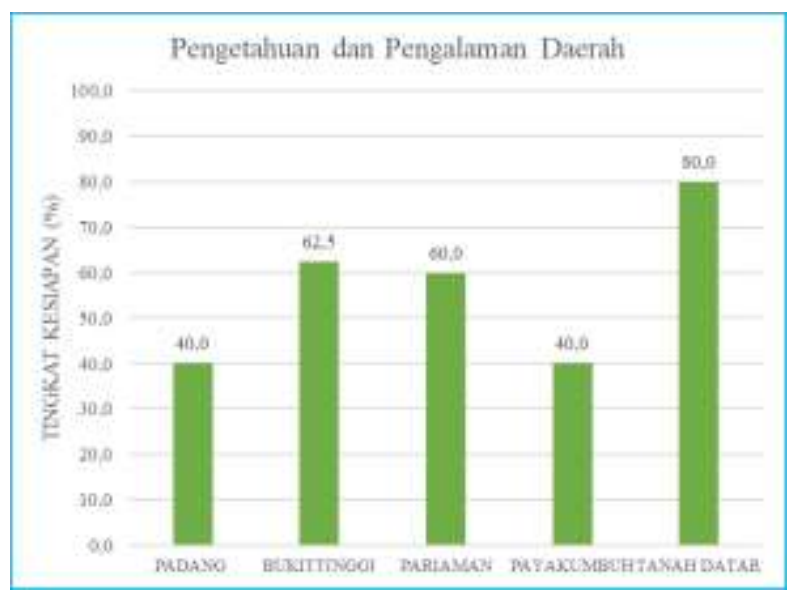

Gambar 5. Tingkat Kesiapan Daerah Berdasarkan Pengetahuan dan Pengalaman Daerah 
Kota Padang memiliki Tingkat Kesiapan CUKUP SIAP artinya agar dapat menjalankan PINA kota padang harus melakukan peningkatan pada beberapa bidang, khususnya bidang SDM dan bidang Pengetahuan dan Pengalaman dalam pelaksanaan PINA.

Kota Bukittinggi memiliki Tingkat Kesiapan SIAP artinya kota Bukittinggi sebenarnya dapat menjalankan PINA, namun agar dapat menjalankan nya dengan baik dibutuhkan beberapa peningkatan pada beberapa bidang khususnya bidang SDM dan bidang Pengetahuan dan Pengalamandalam pelaksanaan PINA.

Kota Pariaman memiliki Tingkat Kesiapan CUKUP SIAP artinya agar dapat menjalankan PINA kota Pariaman harus melakukan peningkatan pada beberapa bidang, khususnya perangkat institusional dan SDM.

Kota Payakumbuh memiliki Tingkat Kesiapan CUKUP SIAP artinya agar dapat menjalankan PINA kota Payakumbuh harus melakukan peningkatan pada beberapa bidang, khususnya bidang Regukasi daerah, perangkat institusional dan pengetahuan mengenai PINA.

Kabupaten Tanah Datar memiliki tingkat Kesiapan SIAP artinya kabupaten tanah datar sudah bisa menjalankan PINA namun agar PINA ini dapat berjalan dengan baik maka kabupaten tanah datar harus melakukan peningkatan pada beberapa bidang.

\section{KESIMPULAN}

Untuk melaksanakan Pembiayaan Infrastruktur Sosial Non-Anggaran maka perlu dicantumkan kebijakan mengenai Pembiayaan Infrastruktur Non-Anggaran dalam Rencana Pembangunan Jangka Menengah Daerah (RPJMD) suatu daerah. Karena, apabila telah dicantumkan dalam RPJMD kebijakan ini dapat menjadi visi dan misi dari daerah tersebut. Ke 19 Kabupaten/Kota di Sumatera Barat belum mengamanatkan status kebijakan mengenai Pembiayaan Infrastruktur Daerah Berbasis Non-Anggaran. Dengan kata lain, Sumatera Barat belum mengamanatkan status kebijakan mengenai Pembiayaan Infrastruktur Daerah Berbasis Non-Anggaran dalam RPJMD. Hal ini dapat disebabkan belum terdiseminasinya pilihan alternatif pembiayaan non-anggaran di Kabupaten/Kota Sumatera Barat.

Kesiapan organisasi pemerintahan untuk berubah mengacu pada seberapa besar anggota organisasi menilai perubahan, bagaimana perubahan tersebut menguntungkan mereka dan bagaimana kemampuan mengimplementasikan perubahan (Guamaradewi \& Mangundjaya, 2018). Untuk itu sangat ditekankan untuk segera dilakukan sosialisasi menyeluruh terkait pembiayaan infrastruktur berbasis non-anggaran ini ke seluruh wilayah, agar daerah dapat segera melakukan kerjasama dengan badan usaha-badan usaha daerah, nasional, ataupun internasional untuk membangun infrastruktur daerah.

\section{DAFTAR PUSTAKA}

Andi (2017). "Mengenal PINA" (http://pina.invest.co.id/2017/02/27/mengenal-pinapembiayaan-investasi-non-anggaran-pemerintah.html), Diakses pada 12 Juli 2017, Pukul 19.46 WIB.

Guamaradewi, N.G \& Mangundjaya, W.L (2018) "Dampak Kesiapan Individu dan Kesiapan Organisasi untuk Berubah bagi Komitmen Afektif untuk Berubah". Jurnal Manajemen Aset Infrastruktur \& Fasilitas Vol. 2, No.2, September 2018 : hal $57-68$.

Kementrian Pekerjaan Umum dan Perumahan Rakyat (2017). "Analisis Investasi Pendanaan Infrastruktur PUPR Kewenangan Daerah". Jakarta.

Martini, S (2011). "Pembiayaan Investasi Sebagai Upaya Mempercepat Penyelenggaraan Infrastruktur Berkelanjutan”. PT Sarana Multi Infrastruktur (Persero).

Northern Ireland Assembly (2016). "Potential of Social Infrastructure Investment to Enhance Social Development and Economic Growth in Northern Ireland". 
Perpres 38/15. Peraturan Presiden No 38 Tahun 2015 tentang Kerjasama Pemerintah Dengan Badan Usaha Dalam Penyediaan Infrastruktur

Prasetyo \& Firdaus (2009). "Pengaruh Infrastruktur Pada Pertumbuhan Ekonomi Wilayah Di Indonesia". Jurnal Ekonomi dan Kebijakan Pembangunan. Vol.2, No.2:222-236.

Rahardjo \& Bermawi (2015). "Strategi Pengelolaan Rantai Pasok Industri Konsruksi Dalam Mendukung Pembangunan Infrastruktur Nasional". Prosiding Seminar Nasional Teknik Sipil V Tahun 2015 - UMS, Surakarta, Indonesia. ISSN: 2459-9727.

Soleh (2005). "Analisis Kesiapan Kabupaten Dalam Menarik Investor, Studi Kasus Kabupaten Temanggung, Jawa Tengah".

Suprayitno, H. \& Soemitro, R.AA. (2018). "Preliminary Reflexion on Basic Principle of Inftratructure Asset Management". Jurnal Manajemen Aset Infrastruktur \& Fasilitas, Vol.2, No.1, Maret 2018:1-9.

Tambunan, T (2006). "Kondisi Infrastruktur Di Indonesia", Kadin Indonesia April 2006. http://www.kadin-indonesia.or.id/enm/images/dokumen/KADIN98-1577-02032007.pdf.

Utomo, W (2016). "Strategi Pembiayaan Dalam Mendukung Pembangunan Infrastruktur Sebagai Bagian dari Smart City". Komite Percepatan Penyediaan Infrastruktur Prioritas (KPPIP). Jakarta. 